\title{
SHARED VISUALIZATIONS IN SUPPORT OF DISTRIBUTED CREATIVE COMMUNITIES
}

\author{
Alastair Weakley, Ernest Edmond \\ Creativity \& Cognition Studios \\ University of Technology, Sydney \\ Australia \\ Email: alastair@weakley.org.uk,ernest@ernestedmonds.com
}

\begin{abstract}
The paper is concerned with support for distributed groups of creative knowledge workers: in this case designers. We consider requirements that designers have regarding internalisation and externalisation of ideas and concepts as well as requirements relating to collaboration. We review an online system whose facilities for the graphical representation of data were found to be popular. The evaluation was in the context of a group task and the results, including instances of tacit knowledge sharing, have led us to formulate a number of recommendations as to how such systems might be made still more effective for collaborative working.
\end{abstract}

\section{Keywords}

Design, creativity, collaboration, distributed groups, support systems

\section{INTRODUCTION}

This paper is concerned with collaboration among distributed, loosely-formed groups whose members are engaged in creative knowledge work. Specifically the interest is with how such groups can, or could, carry out the sorts of knowledge work that are traditionally associated with closelycoupled face-to-face working. In this case, creative knowledge work has been chosen as the domain of study because this type of activity involving, as it does, both problem-setting and problem-solving (Schön, 1983) presents particularly difficult challenges to designers of support systems. In this paper, we consider some specific needs that creative knowledge workers have in relation to externalising, visualizing and communicating concepts and ideas as they develop. We consider how well these needs have been met by existing systems and how future support systems might be made still more effective.

The area of creativity has been the subject of a great deal of research and discussion, and the term can be used to cover a wide range of activities. In this work the specific branch of creative endeavour that has been chosen as the area of study is design. The act of design in this case is defined, following Papanek (Papanek, 1972), as the planning and patterning of any act towards a desired, foreseeable end. We describe some common aspects of design work. Additionally, the nature of groups and group working is considered. In this case, the primary concern is with loosely structured groups rather than well-defined teams. Such groups usually share some common interest or association although this is not necessarily the primary interest of each individual member. Within such a group, associations and links may form and change as work progresses. In particular, this section is concerned with the nature of the communications needed to sustain such relationships. Drawing on the results of an evaluation of the WISA (Web Interactive Scrapbook Application) system, we arrive at some recommendations as to how such systems might be improved. 


\section{VISUALIZATION IN DESIGN:}

Shneiderman (Shneiderman, 2002) identifies eight important 'tasks for creativity'. These are: searching and browsing digital libraries, the Web and other resources; visualizing data and processes to understand and discover relationships; consulting with peers and mentors for intellectual and emotional support; thinking by free associations to make new combinations of ideas; exploring solutions- what-if tools and simulation models; composing artefacts and performances step-by-step; reviewing and replaying session histories to support reflection; disseminating results to gain recognition and add to the searchable resources. Here we are specifically concerned with those relating to visualization.

The organization and analysis of complex data is important at two distinct stages in the type of creative work under consideration here. One the one hand, designers, in their search for knowledge and information that will help them to first understand and then solve the problems with which they are faced, must sift through, and get to grips with large amounts of data. As Shneiderman suggests, visualization of such data can help with organization and understanding: (Shneiderman, 2002) "[d]rawing mental or concept maps of current knowledge helps users organize their knowledge, see relationships and possibly spot what is missing." It is, in the first case, during this investigative process that visualization of complex information can be useful. This process is directed towards understanding and coming to grips with new information and knowledge: internalising it in some way.

There is another area where designers commonly use visualizations of one sort or another. This is in the course of an activity that can be described as 'externalisation'. Here the designer may use models of one sort or another to externalise their ideas, as Shneiderman describes: thinking by free associations and carrying out 'what-if' style investigations. This in turn they may do for two reasons: to allow for visual organization, manipulation or examination of another sort as an aid to understanding as part of the creative process, and also to aid in the communication of ideas to others. Lawson, for example, reports that it is clear from his analysis that "the designer must inevitably expend considerable energy not just in solving but also in identifying the problems confronting him". A large part of the designer's work is in defining and understanding the problem that is to be solved. Often the exact nature of this problem does not become clear until late in the process when a considerable amount of investigation and exploration has already been done. Indeed, design is a process of "incremental formalization" (Gross, 1996) and it is generally accepted that at the start of the process design problems are poorly-defined. Schön (Schön, 1983) describes how design, as well as necessitating finding the solution to a problem, also involves the definition of the problem itself. This problem setting he describes as the means "by which we define the decision to be made, the ends to be achieved, the means which may be chosen."

There are therefore two distinct areas where visualization in some form is important: during the process of internalisation and during the process of externalisation. In the first case, the designers are trying to grasp and assimilate external knowledge and in the second case the knowledge is in some sense, at least in part, already internal. These areas, while distinct and each with their own specific requirements do have certain similarities and so they shall be considered in tandem here. A major concern in this discussion will be the extent to which, and in what ways, technological systems can affect or enhance these processes of internalisation and externalisation.

\section{Examples of Systems Supporting Internalisation}

One recently-developed system is Market Map (Wattenberg, 1999a) described by (Wattenberg, 1999b). Here in an online system data is presented about the New York stock market. The companies themselves are represented as nodes in a treemap (Shneiderman, 1991): each company is 
represented by a rectangle on the screen whose size is proportional to the market capitalization of the company. In turn, the company rectangles are arranged to fill larger rectangles representing each stock market sector (technology, pharmaceuticals and so on). The colours of the rectangles represent the recent changes in the stock price of the company: shades of red represent a fall in price, shades of green a recent rise. As the mouse is moved over each company-rectangle, a box appears showing the company name, the current share price, the amount by which its price has changed in a particular timeframe. A single click on a company-rectangle brings up a menu offering links to greater detail on that company or the market sector to which it belongs: charts, news articles and financial details are all available with one more click. It is possible to move very quickly from a high-level overview down to precise detail on one particular company. This very effective system demonstrates exactly the properties that are desirable in the process of internalisation: a complex mass of data is made rapidly accessible.

(Stappers and Pasman, 2000) describe an interactive system aimed at allowing searches with complex criteria to be carried out easily. In this case, the multidimensional scaling approach is used to display database records arranged, again graphically in this case, according to similarity. Thus, were for example the contents of a database of wines to be displayed, those with similar flavours might be grouped together. To start with, only a few records are displayed. The user may see details of each one. When they click on a gap between records, a new query is generated and executed: a new sample is displayed that most closely matches the query. In this way, to take Stappers and Pasman's example, it would be possible to find a wine 'somewhat sweeter than a Burgundy' from a database of wines, whereas carrying out the same search using text criteria might be very difficult.

\section{Externalisation}

Now we shall consider visualization as applied to externalisation. It is common during, and often as an integral part of, the design process for designers to externalise their thoughts and ideas in the form of models of one sort or another. These models may take many different forms, for example they may be mathematical models, they may be vocal descriptions, they may be physical models or they may be diagrammatical models. Commonly designers will make such re-representations either as an integral part of the design process or in order to share some thought, concept or idea with someone else.

Drawing and sketching, for example, is seen as a very important part of the design process. As Lawson (Lawson, 1990) explains "[t]he whole purpose of doodles, sketches or models is to act as a kind of additional memory to freeze and store spatial ideas which can then be evaluated and manipulated." Schön expands on this describing how these externalisations themselves inform further work. Here he discusses visualisation in the context of architectural design: (Schön, 1992) "A designer sees, moves and sees again. Working in some visual medium .... the designer sees what is 'there' in some representation of a site, draws in relation to it, and sees what he/she has drawn, thereby informing further drawing." Schön describes this process as the designer having a 'reflective conversation' with the representation. It is the two-way nature of the conversation that differentiates this process from the exploration of data made possible by, for example, Market Map. The feedback loop which Schön describes where the designer finds new meaning and understanding in the representation they have created is a key cause of the difference in the representations made and therefore in the requirements for systems that support them. An important point that Schön makes is that it is through the "unintended effects of action" that this new understanding can arise. The act of re-representation in this context is a voyage of discovery and not just one of exploration. It has been the case that traditional computer systems tend to support the process of internalisation more fully than externalisation. However, a number of flexible systems have been developed. Nakakoji and Yamamoto for example present the ART series of systems (Nakakoji and Yamamoto, 2001, 
Yamamoto et al., 2000, Yamamoto et al., 2001, Yamamoto et al., 2003, Yamamoto et al., 2002) which support 2D spatial positioning during the process of creating for example text or multimedia files. As they explain (Yamamoto et al., 2000) 2D spatial positioning can take the place of sketching in domains where sketching is not appropriate. ART stands for 'Amplifying Representational Talkback' and a concern of this work is with how the use of such systems can help to promote the two-way conversations between the user and the representation as described above. In a similar vein, the spatial hypertext editor Tinderbox (Bernstein, 2004) allows arrangements and hierarchies of objects to be viewed in many different ways, and for those objects to be easily and quickly rearranged. Here again, the system offers considerable scope both in terms of what can be represented and how this can be done.

\section{COMMUNICATION IN GROUPS}

Design problems have been described as 'wicked' and it is commonly the case that a single person does not have sufficient skills to solve the problem single-handed (Fischer, 2000). In this paper, the concern is not with well-defined teams of people but with loosely-structured groups: that is groups whose members are for the most part only casually connected. Within this loose structure, group members may seek out collaborators for specific tasks. Closer bonds, then, may form temporarily where members work together on specific problems. This closer work might last for a few weeks or months. In such a group, there is a fluid network of ties of various degrees of strength between members. In addition, members of such groups may also need to interact with individuals outside the group to complete their assignments (Ancona and Caldwell, 1990). As Ancona and Caldwell point out, the more typical model of group work concentrates exclusively on interactions within the group rather than including those that extend beyond its boundary. Yet, these external bonds are crucially important. In fact, it might be more correct to consider the boundary of the group as itself being fluid. As collaborations form new members, possibly whole subgroups, may be temporarily subsumed into or appended to the main group.

(Egido, 1990) notes that '[i]t is often over informal chats outside of official meeting rooms that important information is transmitted and real decisions are made.' She notes that, for example, teleconferencing systems may be unpopular with politically-savvy employees because they do not commonly support such casual interaction.

Kraut, Egido and Galegher (Kraut et al., 1990) found that physical collocation is an important factor in the formation of collaborative partnerships. They studied the frequency of collaborations among researchers whose offices were at a range of distances from one another. Significantly, the distances in question were typically measured in metres rather than kilometres: there was no question of longdistance teleconferencing here. The indications of their research were again that it is often informal interaction, chance meetings and casual discussions that lead to the formation of new relationships. They suggest that the opportunity for casual discussion enables people to discover shared interests and establish common ground with potential collaborators. Where people work at even a relatively short distance from one another, these casual meetings are less likely to happen and so new working relationships are less likely to form. As Kraut et al explain: (Kraut et al., 1990) 'Most often, naturally occurring, informal contact and communication provide the opportunity for potential collaborators to learn about each other, and also serve as the framework within which collaborative tasks are accomplished.'

Rosenberg (Rosenberg, 2001) points out the value of being able to overhear conversations in a shared workspace. As she says, '[i]t is often important for people sharing the same workspace to be aware that a meeting or a conversation is taking place, so that they can join in or leave at appropriate points.' (Perry and Rosenberg, 1998) also suggest that electronic communications media typically do not capture or transmit this valuable information. She says that such systems commonly reduce 
opportunities for informal communication such as: chatting, overhearing conversations, seeing current work laid out on other people's desks, and so on.

Modern technologies have provided ways for us to communicate with others no matter where they are. The use of mobile communications devices, for example, allows us to connect directly to a person wherever they happen to be. In contrast, with the traditional telephone system, we connected to a place in the hope that the person we wanted to speak to was there (Wellman, 2001). Of course this means that we may not initially know the social context of the person we are calling: are they at home or at work for example? It is often the case that such contextual information is not shared when we use modern communications systems. Additionally, (Luff et al., 2003) suggest that it is becoming increasingly evident that interpersonal communication relies on shared access to artefacts within the environment. These might be documents, models, or other physical artefacts, which are either directly the objects of discussion or which are used to clarify points or which passively facilitate communication. (Gaver, 1992), for example points out that face-to-face collaboration is "situated within a shared, encompassing space, one which is rich with perceptual information about objects and events that can be explored and manipulated." We are here concerned not only with talking about these objects, but with using them as shared communicative facilitators: talking through the objects and the surroundings. There are principally three ways in which the environment or environmental artefacts become part of a conversation: when they are, perhaps unconsciously, used to conceptualise a statement, when they are deliberately used to illustrate a point or are themselves the object of discussion, and as passively-informative objects in the environment. We will consider each in turn:

Our environment as a whole particularly contextualizes what we have to say, although, when we are face to face, this is often not explicitly stated nor even consciously registered. As, for example, Sperber and Wilson suggest "a single sentence, with a single semantic representation, can express an unbounded range of thoughts" (Sperber and Wilson, 1986). We can only pin down the meaning when we consider the setting (social as well as physical) in which it is made. Once our communication is decontextualized by separating it from its environment, it can become ambiguous: the communication is compromised.

Churchill explains the role of artefacts that are deliberately used in conversation: (Churchill and Erickson, 2003) "People elaborate on their statements by picking things up or walking around them, by turning them around, by pointing to certain features, by inviting and indicating novel visual stances or perspectives to take, by glancing in the direction of objects as they become the focus of the conversation, and even by turning their backs on them." Here we can see that objects are used to clarify, illustrate and explain; again where parties to the conversation do not all have access to these objects, communication becomes unclear. In a face-to-face setting, it is possible to see where someone is looking, and therefore to work out how an object looks to them. As Kraut et al (Kraut et al., 2003) describe: "[w]hen people can see where each person is looking, it is easier to establish common ground."

A hotel key rack, as (Perry and Rosenberg, 1998) suggests is a good example of a passive environmental communicative shared artifact. By looking at the key rack we can gather a great deal of information. We can tell how many rooms there are in the hotel, and how many of them are occupied, whether a particular person is in or out and whether they have mail. Our worlds are filled with such common artefacts that allow us to deduce useful information about our situations and our surroundings.

A number of systems have been developed with the aim of addressing the issue of sharing such environmental information. Rosenberg and Perry (Perry and Rosenberg, 1998), for example, presents the People and Information Finder (PIF). The PIF is a Web-based system aimed at supporting communication among distributed teams in the construction industry. As they explain, these teams are dynamic or 'agile', typically only being drawn together for a single project. The PIF AJIS Special Issue 
presents information about team members to help in the establishment of common ground. The information is divided into sections: the first consists of data about locating the team member 'in their physical space' : telephone number, address and so on, also included here are photographs and video images showing their offices. Additionally there are team spaces which provide similar information about other teams within the organization. Also it is possible to see page owner's past activities. As Perry and Rosenberg explain: (Perry and Rosenberg, 1998) "the PIF and its underlying informational structure provides a world reduced in detail, but augmented in contextual complexity". Studying such a system allows one to place an individual and a team within the context of their office in the first instance. Seeing images of how this is arranged provides contextual information about that person. Equally the ability to study past work adds important information about their interests and areas of expertise.

Another system, this time slightly more dynamic in its contextualization but in this case providing less detail has been developed by Zhao and Stasko (Zhao and Stasko, 2000). Described as an 'opportunistic peripheral interface' the 'What's Happening?' application displays a small window on the desktop of all its users. In this window appears a scrolling list of announcements. As well as displaying general information: the community calendar, the weather forecast and so on, it is possible for users to add personal information 'it's my birthday' for example. By clicking next to a message users can add comments which everyone can see. As they note, this is a tool aimed at maintaining awareness of what is happening in the distributed community. It is unobtrusive but it provides shared context for future discussions. Strengthening and maintaining common ground by making sure that everyone knows both about important activities, and about personal contextual information on individual group members. This is exactly the sort of background information that can support communication among people who do not share the same environment. In this case, though, the information is not so much related to shared physical artefacts and settings but to shared events.

\section{THE WISA SYSTEM}

WISA, (the Web Interactive Scrapbook Application, described more fully in (Weakley and Edmonds, 2004)) aims to support designers in gathering, organizing and sharing useful resources. The process of design often involves a significant amount of research into new technologies and practices and WISA provides an online facility in which to store and organize references to pictures, people, notes and so on: the results of

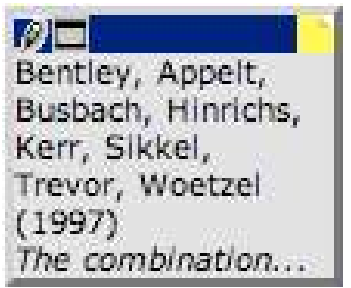
such research. Collections are organized in a series of 'projects' equivalent to pages in a paper scrapbook. Like cuttings in a conventional scrapbook, the individual objects ('resources' in the

Figure 14: Resource Tile 


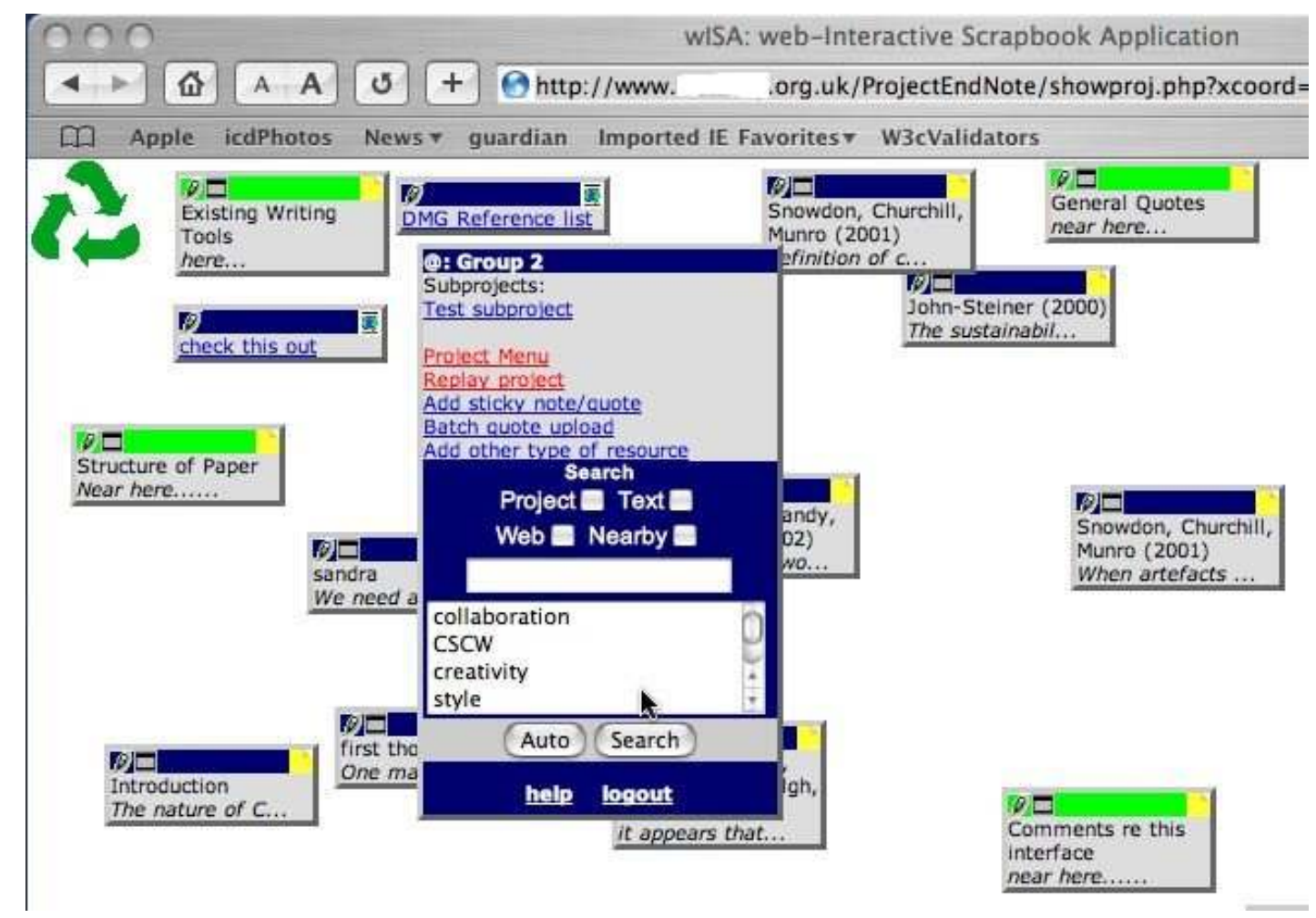

Figure 15: Main Project View 
parlance of this system) can be arranged and grouped in two-dimensional space. Where WISA extends the functionality of the traditional paper scrapbook is in its support for the sharing of resources. WISA can be accessed using a normal Web browser: this makes it possible for several people to share a project and to work on it together from multiple locations. Additionally, it is possible to search for useful material: the contents of all projects in the system are available for searching. In this way, WISA supports members of the group in discovering new, unexpected, information about one another. The system aims not just to support sharing of the information that its users have collected but also to support discovery of common interests and complementary skills. In the WISA system, individual resources are represented as tiles in the project space (see Figure 1: resource tile). Within this space, which represents a single page of the scrapbook, individual tiles can be grouped and rearranged as desired (see Figure 2: ). Tiles are arranged by dragging and dropping, they can also be stacked on top of one another. The position of each tile is recorded along with details about who put it there and when. It is therefore possible to re-enact the development of a project at any time and to see just how the current arrangement of tiles came about. When a project is replayed, the tiles appear in the browser window and move into the positions they occupied as the project developed.

It is by means of this fluid rearrangement that the system aims to support externalisation in the research phases of the design process. The users may experiment with different arrangements and juxtapositions of resource tiles in an attempt to make new associations and connections between them. Additionally, when a search is carried out, data from other group members' projects may be uncovered. It is possible to make such searches sensitive to the spatial arrangements and groupings that these other users of the system have made. When a location-sensitive search is carried out, resource tiles matching the search criteria are displayed together with those that have been placed near to the ones that match. In this way, the system aims to expose associations between objects made by other users. Looking at these connections and groupings allows one to learn about the resource objects themselves as well as about other members of the user group.

Current project: Group 2,

\begin{tabular}{l|l|l|}
\hline Siewing resource: where are you? & Date Made & Made By \\
\hline $\begin{array}{l}\text { This morning time am looking for inspiration for the writing taks but cannot see } \\
\text { whether my coautors have been busy. }\end{array}$ & $\begin{array}{l}2003-09-25 \\
09: 29: 17\end{array}$ \\
\hline
\end{tabular}

Figure 16: Annotation

Each resource tile, as well as containing data such as text or an image, may be annotated by the users of the system (see figure 3: annotation). Many notes may be attached to each tile in a project. Again this supports sharing of information both about the objects in the collection and about the users making the annotation.

AJIS Special Issue

December 2004 


\section{Evaluation of WISA}

In an evaluation (Weakley and Edmonds, 2004), two groups of volunteer users were asked to imagine that they were preparing to write a conference paper. They were invited to use the WISA system to start to build a collection of useful material for their paper. In this case, then the groups were defined at the start and the evaluation therefore concentrated on support for existing groups rather than formation of new relationships.

The users were asked whether they would like to have a text-only display of resources (for example a list) instead of the graphical display. They were also asked if they would have liked a text-only display in addition to the graphical one. In both cases the answer was unanimously 'no' and this clearly indicates that the graphical interface of the WISA system has significant benefits over plain text. Nevertheless, looking at the layout of another person's project was found to be only moderately useful. This raises the interesting question of whether such spatial arrangements may be of greater use for people working on their own, or where their communication is more closely-coupled, such as during a face-to-face meeting, rather than when working in a distributed group where communication relies to a great extent on the visual layout as in this specific case. A number of comments were made about confusion caused when one user rearranged objects in a project and the others did not know the rationale behind the new arrangement. It seems clear that to support group working additional communication facilities must be added to WISA.

There were also instances where users who had previously worked together for some time discovered new common interests, outside the scope of the evaluation, and were able to share information that had been collected and stored in WISA. These connections were made when one user came across an interesting-looking resource belonging to another. It is significant to note that, while these new connections might not have been made without WISA, they were not made by one person interpreting the spatial arrangement made by another. In this sense, the connection could be made independent of a knowledge of context. It was not necessary to know why the interesting resource was present or what purpose it served for its owner its mere presence was sufficient.

WISA has proved to be useful in one sense, but like so many other collaboration support systems it transmits only part of the data. While resources are presented in the context of a project (which is useful to the project's creator), in order to be more useful to others the required context is about the user themselves: this might lead one to an understanding of the reason behind their action. It is the addition of support for this sort of information exchange that should form the basis of future versions of this system. As one of the system's evaluators put it: "There are many depths and features in the background engine which aren't adequately represented in the interface": there is clearly scope to expose more of the information that the system captures.

We can therefore start to formulate recommendations for additional features that might be incorporated in future versions of WISA as follows:

Support direct communication among users

Support awareness of other users' past actions more clearly than at present: what have they done

Support the recording and sharing of information that contextualises the actions of the users: when did they do it and what else were they doing at the same time, for example

Support 'overhearing' among users: provide unobtrusive alerting facilities where possible

Support users in announcing what they are doing or what they require.

\section{CONCLUSION}

We have considered the processes of internalisation and externalisation in the design process and have identified approaches for supporting this. We have also briefly touched upon the needs of 
members of loosely formed groups in particular relating to the sharing of contextual information of various sorts.

In considering the WISA system, we found that it appears to support a personal, reflective approach to internalisation and externalisation and furthermore that it can support the communication and sharing of tacit knowledge among its users. Moreover, evaluation of the system exposed some areas that could be improved. It is clear that the author of a spatial arrangement or grouping of objects in the WISA system may invest in it significances that are beyond those that become apparent to an observer studying the arrangement alone, useful as this may be. Adding contextual information about what the user was doing and why would improve matters. Additionally, returning to the work of Rosenberg and Zhao and Stasko: adding alerting features that would allow one to 'overhear' what another user was engaged in would be useful.

It is clear that whilst the visual layout and sharing of project information presented by a system such as WISA makes an important contribution, it should be seen as only one element in a multi-modal communication facility.

\section{REFERENCES}

Ancona, D. G. and Caldwell, D. F. (1990). Information Technology and Work Groups: The Case of New Product Teams. In Intellectual Teamwork: Social and Technological Foundations of Cooperative Work(Eds, Galegher, J., Kraut, R. E. and Egido, C.) Lawrence Erlbaum Associates, Hillsdale New Jersey, pp. 173-190.

Bernstein, M. (2004). Tinderbox. Eastgate Systems Inc., Watertown, MA.

Churchill, E. F. and Erickson, T. (2003). Introduction to This Special Issue on Talking About Things in Mediated Conversations. In Human Computer Interaction, 18, 1-11.

Egido, C. (1990). Teleconferencing as a Technology to Support Cooperative Work: Its Possiblities and Limitations. In Intellectual Teamwork: Social and Technological Foundations of Cooperative Work(Eds, Galegher, J., Kraut, R. E. and Egido, C.) Lawrence Erlbaum Associates, Hillsdale New Jersey, pp. 351-371.

Fischer, G. (2000). Symmetry of ignorance, social creativity, and meta-design. In KnowledgeBased Systems, 13, 527-537.

Gaver, W. W. (1992). The Affordances of Media Spaces for Collaboration. In CSCW 92 ProceedingsACM Press, pp. 17-24.

Gross, M. D. (1996). The Electronic Cocktail Napkin- a computational environment for working with design diagrams. In Design Studies, 17, 53-69.

Kraut, R. E., Egido, C. and Galegher, J. (1990). Patterns of Contact and Communication in Scientific Research Collaboration. In Intellectual Teamwork: Social and Technological Foundations of Cooperative Work(Eds, Galegher, J., Kraut, R. E. and Egido, C.) Lawrence Erlbaum Associates, Hillsdale New Jersey, pp. 149-171.

Kraut, R. E., Fussell, S. R. and Siegel, J. (2003). Visual Information as a Conversational Resource in Collaborative Physical Tasks. In Human Computer Interaction, 18, 13-49.

Lawson, B. (1990). How Designers Think: The Design Process Demystified. Butterworths, London.

Luff, P., Heath, C., Kuzuoka, H., Hindmarsh, J., Jamazaki, K. and Oyama, S. (2003). Fractured Ecologies: Creating Environments for Collaboration. In Human Computer Interaction, 18, 51-84.

Nakakoji, K. and Yamamoto, Y. (2001). Spatial Positioning as a Representation that Helps us Think. In Position Paper for Hypertext01 Workshop on Spatial Hypertext.

Papanek, V. (1972). Design for the Real World. Thames and Hudson, London. 
Perry, M. and Rosenberg, D. (1998). Configuring a Co-operative Information System - Theoretical and Methodological Issues. In Proceedings of the IIIS'98: Workshop on Innovative Internet Information Systems(Eds, Divitini, M., Brasethvik, T. and Scwartz, D.) Pisa, Italy.

Rosenberg, D. (2001). Communictive Aspects of Social Intelligence. In JSAI-Synsophy International Workshop on Social Intelligence DesignMatsue, Japan.

Schön, D. (1992). Designing as reflective conversation with the materials of a design situation. In Knowledge-Based Systems, 5, 3-14.

Schön, D. A. (1983). The Reflective Practitioner: How Professionals Think in Action. Arena, Ashgate Publishing Limited, Aldershot, UK.

Shneiderman, B. (1991). Tree visualization with treemaps: a 2-d space-filling approach. In ACM Transactions on Graphics, 11, 92-99.

Shneiderman, B. (2002). Creativity Support Tools. In Communications of the ACM, 45, 116-120.

Sperber, D. and Wilson, D. (1986). Relevance: Communication and Cognition. Blackwell, Oxford, UK.

Stappers, P. J. and Pasman, G. (2000). Exploring Databases for Taste of Inspiration with Interactive Multi-Dimensional Scaling. In IEA2000.

Wattenberg, M. (1999a). Market Map. Vol. 2004 www.smartmoney.com.

Wattenberg, M. (1999b). Visualising the Stock Market. In CHI '99 extended abstracts on Human factors in computing systemsACM, Pittsburgh, Pennsylvania, pp. 188-189.

Weakley, A. J. and Edmonds, E. (2004). Web-Based Support for Creative Collaboration. In Proceedings of the IADIS Interantional Conference Web-Based Communities 2004(Eds, Kommers, P., Isias, P. and Nunes, M. B.) IADIS Press, Lisbon, Portugal, pp. 239-246.

Wellman, B. (2001). Physical Place and Cyberplace: The Rise of Personalized Networking. In International Journal of Urban and Regional Research, 25.

Yamamoto, Y., Aoki, A. and Nakakoji, K. (2001). Time-ART: A Tool for Segmenting and Annotating Multimedia Data in Early Stages of Exploratory Analysis. In CHI2001, Extended Abstract.

Yamamoto, Y., Nakakoji, K. and Aoki, A. (2002). Visual Interaction Design for Tools to Think with: Interactive Systems for Designing Linear Information. In Proceedings of the Working Conference on Advanced Visual Interfaces (AVI2002)ACM Press, Torento, Italy, pp. 367 372.

Yamamoto, Y., Nakakoji, K. and Aoki, A. (2003). A Spatial Hypertext Tool for Sculptural Authoring. In Hypertext 2003Nottingham.

Yamamoto, Y., Nakakoji, K. and Takada, S. (2000). Hands-on representations in a two-dimensional space for early stages of design. In Knowledge-Based Systems, 13, 375-384.

Zhao, Q. A. and Stasko, J. T. (2000). What's Happening? The Community Awareness Application. In CHI ' 00 extended abstracts on Human factors in computing systemsACM Press, The Hague, The Netherlands, pp. 253-254.

\section{COPYRIGHT}

Alastair Weakley, Ernest Edmonds (C) 2004. The authors assign to OZCHI and educational and nonprofit institutions a non-exclusive licence to use this document for personal use and in courses of instruction provided that the article is used in full and this copyright statement is reproduced. The authors also grant a non-exclusive licence to OZCHI to publish this document in full in the Conference Papers and Proceedings. Those documents may be published on the World Wide Web, CD-ROM, in printed form, and on mirror sites on the World Wide Web. Any other usage is prohibited without the express permission of the authors. 